\title{
Is Laparoscopic Cholecystectomy a Safe Method For Elderly Patients? A Retrospective Clinical Study
}

\author{
Feyzi Kurt \\ Department of General Surgery, Seyhan State Hospital, Adana, Turkey
}

\begin{abstract}
As in developed countries, the elderly population is gradually growing in our country. Therefore, the approach to diseases of these individuals may be different from adults and young individuals. Acute cholecystitis is common in elderly patients and may sometimes pose a high risk. In this clinical study, we aimed to compare our surgical treatment outcomes for acute cholecystitis in elderly and adult patients.

The study included 225 patients who were operated with the diagnosis of acute cholecystitis in the General Surgery Clinic of Seyhan State Hospital between 2013 and 2019. The patients were divided into 2 groups according to their ages. The group 1 consisted of patients aged 75 years and older, while the group 2 included patients younger than 75 years of age. The patient data were obtained by scanning the database. The preoperative and postoperative data of the patients were recorded. The patients' age, morbidity, mortality and duration of hospital stay were compared.

When the patients in the elderly ages were investigated with the subjects in the adult group, there was no statistically meaningful difference between the subjects in terms of conversion from laparoscopic to open surgery, bleeding, bile leak, abscess and peritoneal collection. Our mortality and morbidity rates were not differ in both groups and were consistent with the literature.

Elderly patients with acute cholecystitis can be managed laparoscopically, as in other adult patients. Treatment approaches do not vary for elderly and young patients.
\end{abstract}

Key Words: Acute cholecystitis, laparoscopic cholecystectomy, elderly patients, emergency

\section{Introduction}

The proportion of elderly population is gradually rising in developed and developing societies. (1) In parallel with the increase in elderly population, the number of chronic diseases increases, which may complicate the treatment of patients with acute cholecystitis. Acute cholecystitis results from obstruction of the cystic duct or the junction between the cystic duct and choledoch by a stone or edema. (2) Complications such as sepsis, peritonitis, gallbladder perforation, abscess and cholangitis occur more frequently in the elderly due to acute cholecystitis. (3) The standard treatment of acute cholecystitis is surgery, which can be performed as laparoscopic cholecystectomy or open cholecystectomy. (4) Although laparoscopic cholecystectomy can be performed safely by experienced surgeons, morbidity and mortality rates are still high in elderly patients. (5) In the literature, some studies have reported a rather high mortality rate like 30\% after cholecystectomy in elderly patients with a critical general condition. (6) Therefore, in addition to those who recommend conservative parenteral antibiotic treatment for acute cholecystectomy instead of cholecystectomy, there are also authors who surgically prefer percutaneous cholecystectomy. $(7,8)$ Laparoscopic cholecystectomy is a usable standard method in elderly patients due to the increase in laparoscopic experience of surgeons.

In this study, we aimed to compare our surgical treatment outcomes for acute cholecystitis in elderly and younger patients.

\section{Materials and Methods}

The study included 225 patients who were operated for acute cholecystitis between January 2013 and March 2019 in the General Surgery Clinic of a State Hospital. The data of the patients were obtained using the electronic database. The patients' gender, age, preoperative findings, surgical treatments, operative times, morbidity, mortality, and length of hospital stay were recorded. The diagnosis of acute cholecystitis was clinically made based on upper quadrant pain, positive Murphy's sign, nausea, vomiting and fever, and a WBC count above $120,000 / \mathrm{microL}$ and/or a CRP level above $3 \mathrm{mg} / \mathrm{L}$ in laboratory findings, and stone along with distended gallbladder, wall thickening, and pericholecystic fluid presence on ultrasonography. ASA (American Society 
of Anesthesiologist) physical status classification system was used to assess preoperative anesthesia risk status of the patients. The patients diagnosed with acute cholecystitis were divided into two groups according to their ages. The group 1 included the patients aged 75 years and older, while the group 2 included patients younger than 75 years of age. The preoperative characteristics of the patients in both groups, such as age, gender, ASA score, as well as type of surgery performed, operative time, morbidity, mortality and length of hospital stay were compared (Table 1, 2).

Analysis of Data: The SPSS (Statistical Package for Social Sciences) 20.0 for Windows was used. Normal distribution of variables was checked. The t-test was used for the analysis of normally distributed continuous variables, while the Mann-Whitney U Test was used for the analysis of non-normally distributed variables. The results were expressed as mean \pm standard deviation, $\mathrm{n}$ and percentage (\%). A $\mathrm{p}$ value of $<0.05$ was considered statistically significant.

\section{Results}

The study included 235 patients operated with the diagnosis of acute cholecystitis. Of the patients, 127 (54.04\%) were female and 108 (45.95\%) were male. The mean age of the patients was 64.02 years (range, 18-96). The mean age of the female patients was 65.62 years, while the mean age of the male patients was 62.42 years. There were 51 patients $(21.70 \%)$ in the group 1 and 184 patients $(78.29 \%)$ in the group 2 (Table 1). The mean age of the patients in the group 1 was 81.42 years (range, $75-88$ years). The mean age of the patients in the group 2 was 46.76 years (range, 18-74 years). Twenty-five patients had stone in the choledoch as the radiological diagnosis. Seven $(13.72 \%)$ patients in the group 1 and $18(9.78 \%)$ patients in the group 2 underwent endoscopic retrograde cholangiopancreatography (ERCP) for common bile duct stone. All patients who underwent ERCP then underwent laparoscopic cholecystectomy. Laparoscopic cholecystectomy was converted to open surgery in $3(12 \%)$ of the patients who underwent ERCP. Of the patients in the group 1, $10(19.60 \%)$ had an ASA score of 1-2, while $41(80.39 \%)$ had an ASA score of 3-4. In the second group, $162(88.04 \%)$ patients had an ASA score of 1-2, while $22(9.78 \%)$ patients had an ASA score of 3-4 (Table 1). This was statistically significant. However, there was no statistical difference between the two groups in terms of mortality and morbidity. Eight (15.68\%) patients in the group 1 and $24(13.04 \%)$ patients in the group 2 underwent open cholecystectomy due to previous abdominal surgery. Laparoscopy was converted to open surgery in 4 patients $(10.25 \%)$ in the group 1 and 12 patients $(8.10 \%)$ in the group 2 . There was no statistically significant difference between the two groups. The mean operative time was 35.64 minutes (min: 21 min.-max: $62 \mathrm{~min}$ ) in the group 1 and 30.28 minutes (min: 20 min.-max: $72 \mathrm{~min}$.) in the group 2 . The patients' mean length of hospital stay was 2.3 days in the group 1 and 1.82 days in the group 2 (Table 2). Although the mean operative time was longer in the group 1, this was not statistically significant. Although the mean length of hospital stay was longer in the group 1, this was also not statistically significant. In the group 1 , one patient was lost due to cardiac causes and the other patient was lost due to respiratory causes. In the group 2, there were no patients who died. This rate was also not statistically significant.

\section{Discussion}

Cholelithiasis is a common disease and its incidence increases with age. The incidence of this disease is about $12-15 \%$ in females and $3-10 \%$ in males under the age of 50 years. In the elderly, this rate increases up to $50 \%$ in males and $15 \%$ in females. (9) However, the incidence of acute cholecystitis also increases with age. (10) Although there are controversies regarding the treatment of acute cholecystitis in the literature, open and laparoscopic cholecystectomy are the most commonly preferred methods. (11)

The rate of co-morbidity increases in patients with age. At the same time, these patients develop limitations in physiological functions. Therefore, a number of systemic complications are more common in these patients. This is a matter of debate as to which is the best treatment method for these patients. (12) However, the randomized studies conducted by Taragona et al. in 1996 and Boerma et al. in 2002 concluded that the best method for these patients is laparoscopic cholecystectomy, if there is no pathology in the bile ducts or after sphincterectomy is performed. $(13,14)$

Concomitant diseases may lead to complications in these patients during and after surgery. (15) Although the morbidity rate of the elderly group was high in our study, it was not statistically significant. Numerous studies in the literature suggested that the best method for elderly patients with acute cholecystitis is cholecystectomy. (16) However, morbidity and mortality rates are higher in these patients than in adult patients. But this rate is not statistically significant and is within the acceptable limits.

In our study, the sample size was less than the sample 
Table 1. Preoperative findings of patients

\begin{tabular}{lccc}
\hline & Group 1 (75 years of age and older) & Group 2 (under 75 years of age) & P \\
$\mathrm{N}=51$ & $\mathrm{~N}=184$ & \\
\hline $\mathrm{M}$ & $16(31.37 \%)$ & $52(28.26 \%)$ & 0.56 \\
$\mathrm{~F}$ & $35(68.62 \%)$ & $132(71.73 \%)$ & 0.73 \\
ASA 1-2 & $10(19.60 \%)$ & $162(88.04 \%)$ & 0.02 \\
ASA 3-4 & $41(80.39 \%)$ & $22(11.95 \%)$ & 0.03 \\
ERCP (common & $7(13.72 \%)$ & $18(9.78 \%)$ & 0.07 \\
bile duct stone) & & & \\
\hline
\end{tabular}

$\mathrm{P}<0.05$ indicates statistical significance

Mann-Whitney test was used for statistical comparison

Table 2. Postoperative findings of patients

\begin{tabular}{lccc}
\hline & $\begin{array}{c}\text { Group 1 (75 years of age and older) } \\
\mathrm{n}=51\end{array}$ & $\begin{array}{c}\text { Group 2 (under } 75 \text { years of } \\
\text { age }) \\
\mathrm{n}=184\end{array}$ & $\mathrm{p}$ \\
\hline Open surgery & $8(15.68 \%)$ & $24(13.04 \%)$ & 0.067 \\
Laparoscopic surgery & $39(76.47 \%)$ & $148(80.43 \%)$ & 0.056 \\
Conversion to open surgery & $4(10.25 \%)$ & $12(8.10 \%)$ & 0.084 \\
Postop. bleeding & 1 & 2 & - \\
Bile leak & 1 & 3 & - \\
Peritoneal abscess & - & 2 & - \\
Cardiac problems & 2 & 1 & - \\
Respiratory problems & 2 & 1 & 0.054 \\
Morbidity & $6(11.76 \%)$ & $9(4.89 \%)$ & 0.08 \\
Mortality & $2(3.92 \%)$ & $(0.00 \%)$ & 0.06 \\
Operative time & 35.64 minutes & 30.28 minutes \\
Length of hospital stay & 2.3 days & 1.82 days & 0.072 \\
\hline
\end{tabular}

sizes in the literature. This may be a limitation of our study. Despite that, our morbidity and mortality rates were consistent with that of the literature. The mean operative time and length of hospital stay were similar in both groups. The difference between the groups was not statistically significant.

In this clinical study, we concluded that surgical treatment of acute cholecystitis can be performed safely in the elderly just as in adults. The morbidity and mortality of surgical procedures for acute cholecystectomy are higher in the elderly compared to adults. However, this difference is due to a number of additional health problems seen in the elderly rather than direct surgical procedures. The treatment of acute cholecystitis is laparoscopic cholecystectomy in eligible patients and can also be performed safely in the elderly.

\section{References}

1. Kuy S, Sosa J.A, Roman S.A, Desai R., Rosenthal RA, Age matters: a study of clinical and economic outcomes following cholecystectomy in elderly Americans. Am J. Surg 2011; 201: 789-7986.

2. Maekawa S, Nomura R, Murase T, Ann Y, Oeholm M, Harada M. Endoscopic gallbladder stenting for acute cholecystitis: a retrospective study of 46 elderly patients aged 65 years or older. BMC Gastrol 2013; 13: 65.

3. Indar AA, Beckingham IJ. Acute cholecystitis. BMJ 2002; 325: 639-643.

4. Hirota M, Takada T, Kawara Y, et al. Diagnostic criteria and severity assessment of acute cholecystitis: Tokyo Guidelines. J Hepatobiliary Pancreat Surg 2007; 14: 78-82.

5. Frazee RC, Nagorney DM, Mucha P Jr. Acute acalculous cholecystitis. Mayo Clin Proc 1989; 64: 163-167.

6. Patterson EJ, Mcloughlin RF, Mathieson JR, Cooperberg PL, Macfarlane JK. An alternative approach to acute cholecystostomy and interval laparoscopic cholecystectomy. Surg Endosc 1996; 10: 1185-1188.

7. Gunay Y, Emek E, Bircan HY, Aktas S, Demirag A. Yaşlılarda akut kolesistit tedavisine yaklaşım: perkütan kolesistostomi veya kolesistektomi. Firat

East J Med Volume:25, Number:2, April-June/2020 
Feyzi Kurt / Laparoscopic cholecystectomy in elderly

Tip Dergisi 2013; 18: 239-243.

8. Cheng WC, Chiu YC, Chuang CH, Chen CY. Assessing clinical outcomes of patiens with acute calculous cholecystitis in addition to the Tokyo grading: a retrospevtive study. Kaohsiung J Med Sci 2014; 30: 459-465.

9. Halldestan I, Enell, Kullman E, Borch K. Development of symtoms and complications in individuals with asymptomatic gallstones. $\mathrm{Br} \mathrm{J}$ Surg 2004; 91: 734-738.

10. Rispoli C, Rocco N, Iannone L, et al. Developing guidelines in geriatric surgery: role of the grade system. BMC Geriatr. 9 (Suppl.1) (2009) A98.

11. Agrusa A, Romano G, Frazzetta G, et al. Role and outcomes of laparoscopic cholecstectomy in elderly. International Journal of Surgery 2014; 12 : 537-539.

12. Marcari RS, Lupinacci RM, Nadal LR, Rego RE, Coelho AM, de Matos Farah JF. Outcomes of laparoscopic cholecystectomy in octogenarians.
JSLS 2012; 16: 271-275.

13. Targarona EM, Ayuso RM, Bordas JM, et al. Randomised trial of endoscopic sphincterotomy with gallbladder left in situ versus open surgery for common bileduct in high-risk patients. Lancet 1996; 347: 926-929.

14. Boerma D, Rauws EA, Keulemans YC, et al. Waitand-see policy or laparoscopic cholecystectomy after endoscopic sphincterotomy for bile-duct stones: a randomised trial. Lancet 2002; 360: 761 765.

15. Nielsen LB, Harboe KM, Bardram L. Cholecystectomy for the elderly: no hesitation for otherwise healthy patients. Surg Endosc 2014; 28: 171-177.

16. Rao A, Polanco A, Qiu S, et al. Safety of outpatient laparoscopic cholecystectomy in the elderly: analysis of 15,248 patients using the NSQIP database. J Am Coll Surg 2013; 217: 1038 1043. 